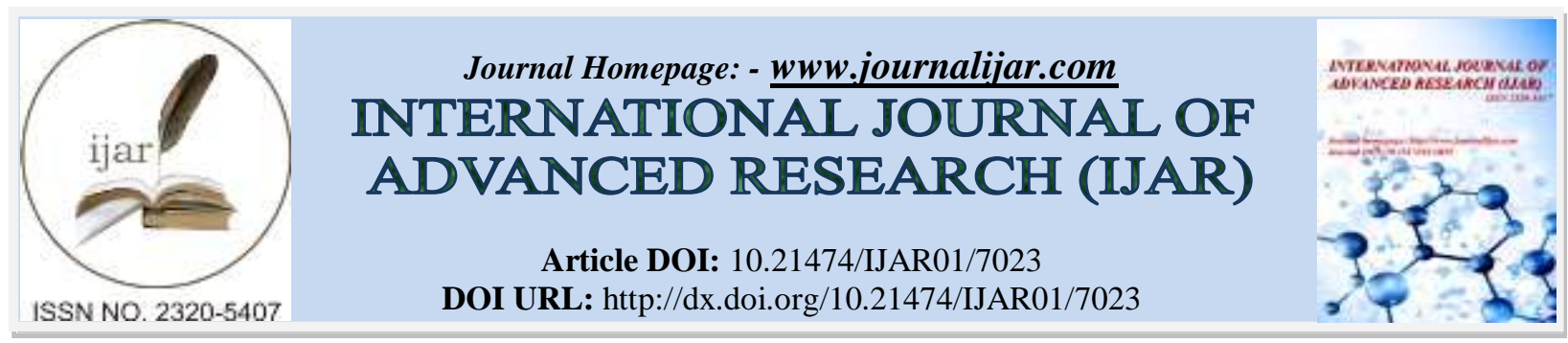

RESEARCH ARTICLE

\title{
QUALITATIVE AND QUANTITATIVE ANALYSIS OF DIFFERENT MORPHOLOGIES OF TIO NANOTUBES USING FE-SEM-EDS
}

Hawraa Q M. Al-Furaiji and "Zainab T. YAl-Abdullah.

University of Basrah College of education of pure science chemistry department.

\section{Manuscript Info}

Manuscript History

Received: 03 March 2018

Final Accepted: 05 April 2018

Published: May 2018

Keywords:-

$\mathrm{TiO}_{2}$ nanotubes, Anodisation, FE- SEM,

EDS, drug release.

\begin{abstract}
We report the preparation of $\mathrm{TiO}_{2}$ nanotubes by anodisation method in which the inner diameter vary depending on the distance between the anodisation electrodes. Nanotubes create by different anodisation distance between the electrodes have different inner and outer diameter that means they have different morphologies. A field emission scanning electron microscope FE- SEM was employed for the morphological characterization of $\mathrm{TiO}_{2}$ nanotubular layers however; FE- SEM -EDS was employed for the qualitative and quantitative analysis of nanotubes. The synthesised nanotubes were used to control the release kinetics of methylene blue in aqueous media. Methylene blue was used to simulate the drug. The results show the possibility of using the controlling drug release by control the inner and outer diameter of $\mathrm{TiO}_{2}$ nanotubes mouth.
\end{abstract}

Copy Right, IJAR, 2018,. All rights reserved.

\section{Introduction:-}

In the past few years, Nanotechnology is one of the most extraordinary fields for producing the latest applications. The most prevalent promising approach of nanotechnology is the production of nanotubes. These one-dimensional nanostructures provide special electronic properties, which involve high electron mobility or quantum confinement effects, very high specific surface area, and self-organized nano-scale structures on metals or semiconductors which produce much consideration due to the scientific importance and the potential applications. Lately, a novel form of valve metal oxide nanostructure has been developed according to anodisation. Over exact anodic conditions in electrolytes containing fluoride, highly organized arrays of oxide nanotubes could grow on different metals such as $\mathrm{Ti}[1], \mathrm{Zr}$ and $\mathrm{W}[2,3]$. Particularly, $\mathrm{TiO}_{2}$ nanotubes formed on have attracted great attention in the past years due to their variety of functional properties and potential applications, such as gas sensing [4] catalysis [5], solar cell [6] and biocompatible materials [7]. As an effective formation method of $\mathrm{TiO}_{2}$ nanotubes, the anodisation process is beneficial because of simple production and cheap cost. The geometry of $\mathrm{TiO}_{2}$ nanotube gives the specific control of the nanotubes such length and diameter permits different applications. The geometry of $\mathrm{TiO}_{2}$ nanotube as a membrane makes it appropriate for placement for both biomedical implant and injected capsules [8] [9] [10] [11] [12]. The diameter and the length depend linearly on the voltage [13]. The results indicate what essentially affects the tube length is the field strength which influences ion migration in electrolyte and ion transport in anodic barrier layer [14]. The prepared tubes was applied for different field such photocatalytic compounds [15], [16], drug release[17] and medical application [18]. Biomaterials polymers were also used for releasing the drugs [19], [20]. The work illustrated in this paper is study the kinetic of $\mathrm{MB}$ release from $\mathrm{TiO}_{2}$ nanotubes that were synthesized by anodisation with particular control. 


\section{A. EXPERIMENTAL2.}

The Ti foils $(0.1 \mathrm{~mm}$ thick, $99.6 \%$ purity) were first polished by diamond paste type [(Grande:1-MWO $)(\mathrm{S}$ Lot No:60.103)(Net :5g)]). It degreased prior to anodisation by sonicating in acetone then rinsed with deionised water. The electrochemical set-up consisted of a DC high-voltage potentiostat $(65 \mathrm{~V})$ and leaving the electrodes with different distances $(5.5,6.5,7.5 \mathrm{~cm})$ and Ti surface is $(1) \mathrm{cm}^{2}$ open to the electrolyte. The nanotubes were created by anodisation for 1 hour. The Ti plates were used as anode and cathode, immersed in electrolyte contain $(0.7 \% \mathrm{w} / \mathrm{w})$ ammonium fluoride, $(2 \% \mathrm{w} / \mathrm{w})$ water and $(97.3 \% \mathrm{w} / \mathrm{w})$ ethylene glycol. A field emission scanning electron microscope was employed for the morphological characterization of $\mathrm{TiO}_{2}$ nanotubular layers. Moreover, EDS used for elemental analysis of $\mathrm{TiO}_{2}$ nanotubes which prepared by different distance between electrodes. For release study the titanium plates were dipped in methylene blue solution with concentration (50 ppm) the dipping time was 24 hour. The Ti plate then rinsed by deionised water and dried in air. After that the release was measured in $25 \mathrm{ml}$ deionised water. The dipped and dry arrays were coated by poly vinyl alcohol by dipping, followed by left to dry in air. The release was measured by UV-viz spectrophotometer.

\section{Result and Discussion:-}

\section{B. 3.1 Anodisation method}

Anodisation can be categorized as one of the most basic, low cost and most straight-forward approaches to develop ordered porous nanostructures under proper conditions. Anodisation method was applied in order to form $\mathrm{TiO}_{2}$ nanotubes as seen in Figure (1).

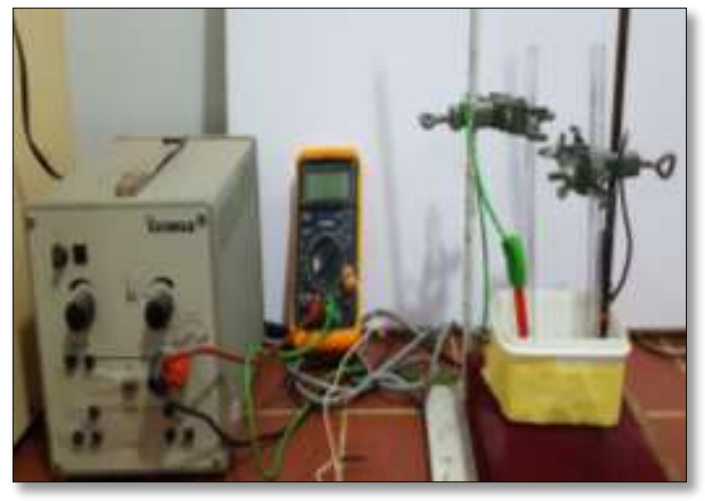

Figure (1):- shows anodisation unit used for synthesis $\mathrm{TiO}_{2}$ nanotubes.

In the anodisation process water in the solution reacts with the titanium metal surface leading to the formation of oxide layer under an applied electric field as seen in equation1.

$$
\mathbf{T i}+2 \mathrm{H}_{2} \mathbf{O} \rightarrow \mathrm{TiO}_{2}+4 \mathbf{H}^{+}+4 \mathbf{e}^{-}
$$

$\mathrm{TiO}_{2}$ oxide layer is then etched into as it is dissolved with assistance of fluoride ions as seen in equation 2 .

$$
\mathrm{TiO}_{2}+6 \mathrm{~F}^{-} \rightarrow\left[\mathrm{TiF}_{6}\right]^{-2}
$$

A great advantage of anodisation is their ability to tune the size and shape of nanotubular arrays on varied kinds of materials, for example, metals and metal alloy substrates, to achieve precise dimensions, satisfying the supplies of specific applications by means of controlled anodic oxidation.

\section{Characterisation of $\mathrm{TiO}_{2}$ nanotubes using FE-SEM3.2}

The shape and size of $\mathrm{TiO}_{2}$ nanotubes were examined clearly under field emission scanning electron microscope (FE-SEM). The SEM images in (Figure 2) show that the tubes are self ordered and cylindrical in shape. The average tube length and the average diameters of the tubes were shown in table1. 


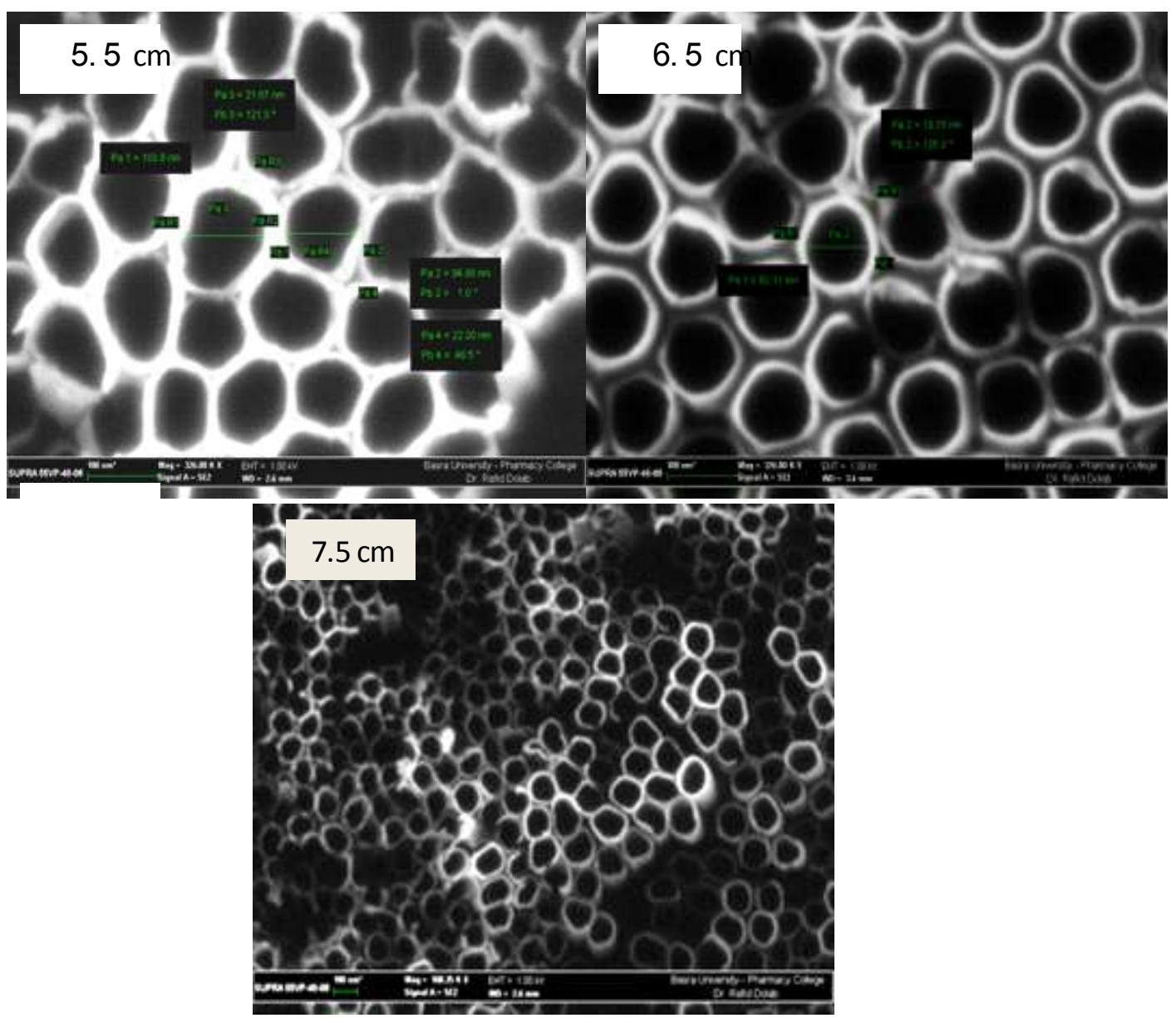

Figure2:- FE-SEM images of top-view $\mathrm{TiO}_{2}$ nanotubes creates at different distance between the electrodes.

Table 1: $\mathrm{TiO}_{2}$ nanotubes diameters at different distance between electrodes.

\begin{tabular}{|l|l|l|}
\hline Samples according to distance $(\mathrm{cm})$ & Outer diameter(nm) & $\begin{array}{l}\text { Inner diameter } \\
(\mathrm{nm})\end{array}$ \\
\hline 5.5 & 159 & 104 \\
\hline 5 & 101 & 82 \\
\hline 7.5 & 80 & 67 \\
\hline
\end{tabular}

\section{3.3 Contact angle measurements}

The contact angle was measured in order to study the hydrophilicity of the surface. If the contact angle between the drop of liquid and the titanium surface is less than 90 degrees, the liquid is said to wet the solid. If it is greater than 90 degrees, it is said to be non-wetting. A zero contact angle represents total wetting [21].

Table 2 shows the contact angle measurement of photographic image for methylene blue droplet on the $\mathrm{TiO}_{2}$ nanotubes arrays. This study shows that the tubes with biggest diameter hascontact angle bigger. 


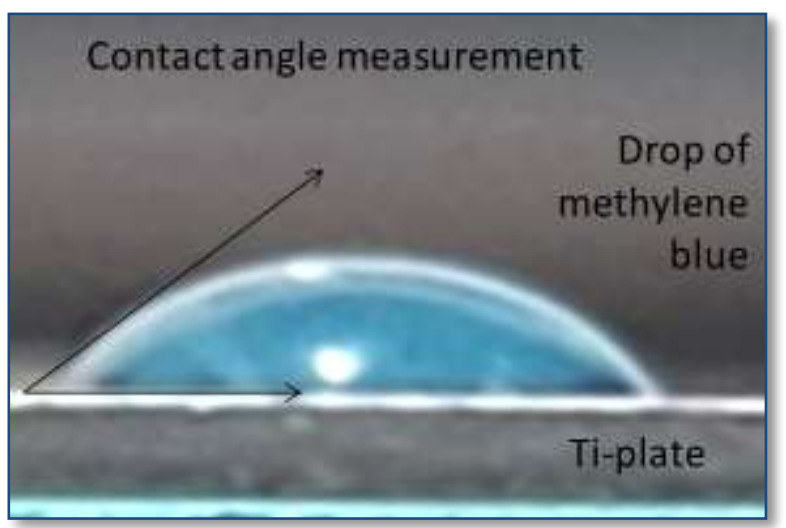

Figure 3:- The photoimage of drop of methylene blue on $\mathrm{TiO}_{2}$ nanotubes arrays.

Table2:- the measurement of contact angle of methylene blue on the $\mathrm{TiO}_{2}$ nanotubes arrays.

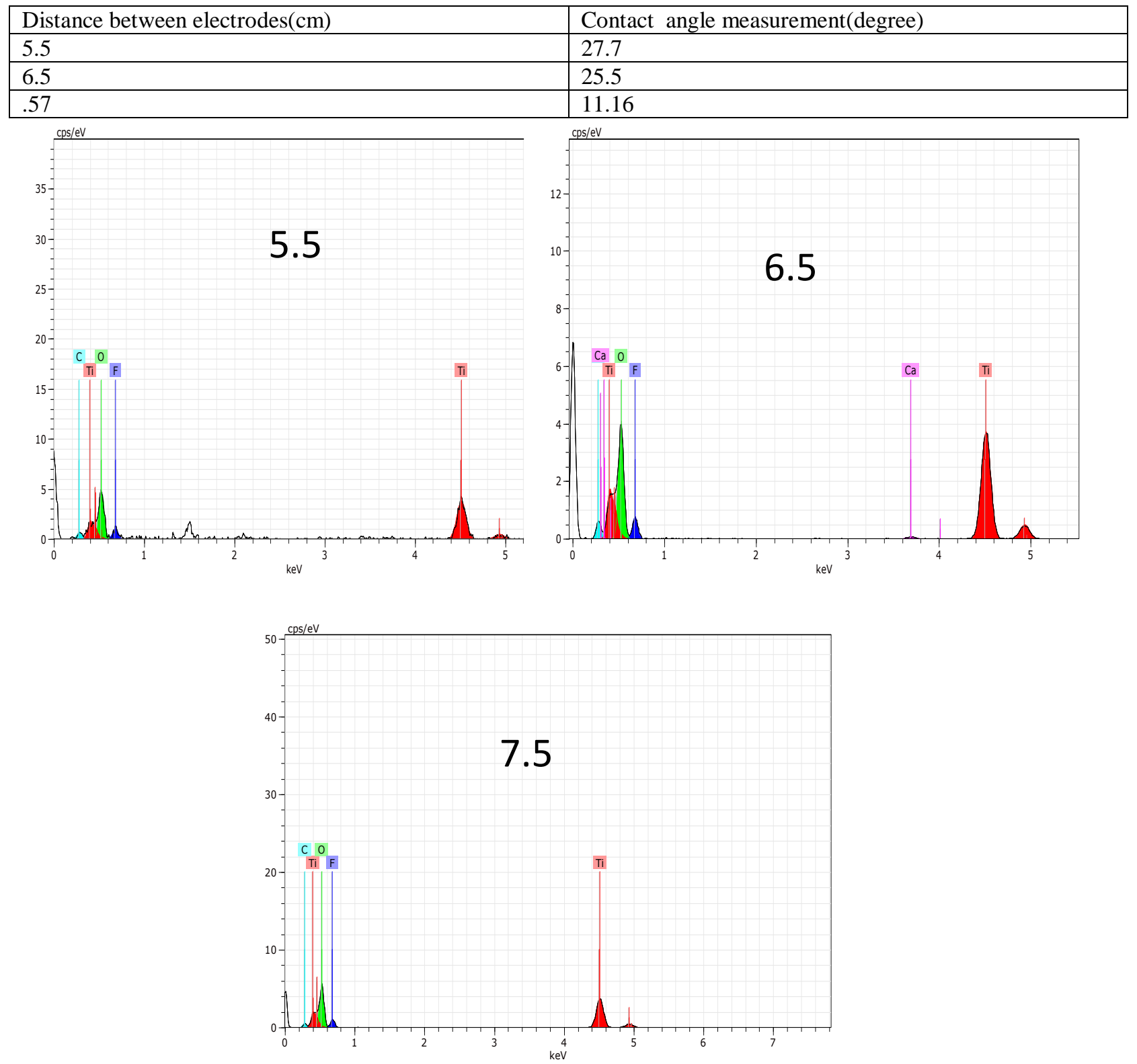


Figure4:- EDS spectrum of of $\mathrm{TiO}_{2}$ nanotubes array at different distance of electrodes during the anodisation process.

E. 3.4 Energy Dispersive X-ray Spectroscopy (EDS) analysis

Energy dispersive X-ray spectroscopy is a useful analytical technique to analyze the chemical elements and compositions in the sample. EDs spectra for the synthesized nanotubes is shown in Figure (4). Form the EDS result confirms the presence of $\mathrm{Ti}$ and $\mathrm{O}$ as elementary components in the synthesized $\mathrm{TiO}_{2}$ nanotubes. The data of atomic percentage(w/w) obtained from EDS spectrum of the synthesized nanotubes are listed as an insert (table3) of Figure 4. The obtained values are nearly close to $1 / 2$ agreeing with the expected chemical composition of normal structure of synthesized nanotubes, with good result of purity of arrays hence the spectra was taken on carbon grid.

Table 3: The elemental analysis of $\mathrm{TiO}_{2}$ nanotubes synthesised by anodisation with the distance between the electrodes $5.5 \mathrm{~cm}, 6.5 \mathrm{~cm}, 7.5 \mathrm{~cm}$.

\begin{tabular}{|c|c|c|c|c|c|c|}
\hline Element & Series & $\begin{array}{l}\text { unn. C } \\
{\left[w t . \frac{\circ}{0}\right]}\end{array}$ & $\begin{array}{l}\text { norm. C } \\
{\left[w t \cdot \frac{\circ}{0}\right]}\end{array}$ & $\begin{array}{l}\text { Atom. C } \\
{[a t . \circ]}\end{array}$ & $\begin{array}{l}\text { Spectru } \\
\text { Error }\end{array}$ & $\begin{array}{l}\text { am: } 5.5 \\
\text { Sigma) } \\
{[w t . \circ]}\end{array}$ \\
\hline Titanium & K-series & 55.25 & 55.50 & 29.55 & & \\
\hline Oxygen & K-series & 34.22 & 34.38 & 54.79 & & 28 . \\
\hline Fluorine & K-series & 7.44 & 7.48 & 10.03 & & 10.6 \\
\hline Carbon & K-series & 2.64 & 2.65 & 5.63 & & 4.83 \\
\hline
\end{tabular}

\begin{tabular}{|c|c|c|c|c|c|c|}
\hline Element & Series & $\begin{array}{l}\text { unn. C } \\
{\left[w t . \frac{\circ}{0}\right]}\end{array}$ & $\begin{array}{l}\text { norm. C } \\
{\left[w t . \frac{\circ}{0}\right]}\end{array}$ & $\begin{array}{l}\text { Atom. C } \\
{[a t . \circ]}\end{array}$ & $\begin{array}{l}\text { Spectru } \\
\text { Error }\end{array}$ & $\begin{array}{c}\text { Am: } 6.5 \\
\text { Sigma) } \\
{[w t . \circ]}\end{array}$ \\
\hline & & & & & & \\
\hline $\begin{array}{l}\text { itanium } \\
\text { xygen }\end{array}$ & K-series & $5 \% \cdot 32$ & $\begin{array}{l}58.43 \\
32.66\end{array}$ & $\begin{array}{l}32.10 \\
53.69\end{array}$ & & \\
\hline Fluorine & K-series & 5.67 & 5.78 & 8.00 & & \\
\hline Carbon & K-series & 2.66 & 2.71 & 5.93 & & 1. \\
\hline Calcium & K-series & 0.42 & 0.43 & 0.28 & & 0.1 \\
\hline
\end{tabular}

\begin{tabular}{|c|c|c|c|c|c|c|}
\hline Element & Series & $\begin{array}{l}\text { unn. C } \\
{\left[w t . \frac{\circ}{0}\right]}\end{array}$ & $\begin{array}{l}\text { norm. C } \\
{\left[w t . \frac{\circ}{0}\right]}\end{array}$ & $\begin{array}{r}\text { Atom. C } \\
{\left[\text { at. } \frac{\circ}{0}\right]}\end{array}$ & $\begin{array}{l}\text { Spectru } \\
\text { Error }(3\end{array}$ & $\begin{array}{l}\text { am: } 7.5 \\
\text { Sigma) } \\
\text { [wt. } \% \text { ] }\end{array}$ \\
\hline & & & & ----- & & -- \\
\hline Titanium & K-series & 55.48 & 52.43 & 27.11 & & 5 . \\
\hline Oxygen & K-series & 40.29 & 38.07 & 58.91 & & 14.52 \\
\hline Fluorine & K-series & 7.82 & 7.39 & 9.63 & & \\
\hline Carbon & K-series & 2.24 & 2.11 & 4.35 & & 1.18 \\
\hline
\end{tabular}




\section{F. .5The Release kinetics of $M B 3$}

Synthesis of $\mathrm{TiO}_{2}$ nanotubes was applied on drug release activity. Standard drug release measurements are typically made in media such as saline, water or other buffered aqueous solutions [22]. In our experiments methylene blue absorbance was measured in the range of (0-10) ppm. Release kinetics, was measured in (25) ml deionised water. The concentrations of released MB were measured by UV-Vis spectrometry at (665) nm where the MB has maximum absorbance. Under controlled parameters, MB elution was precise at a variety of time, after which the MB concentration reached an area of constancy and release accomplished. Figure 5 and figure 6 show the calibration graph for MB and the maximum absorbance respectively.

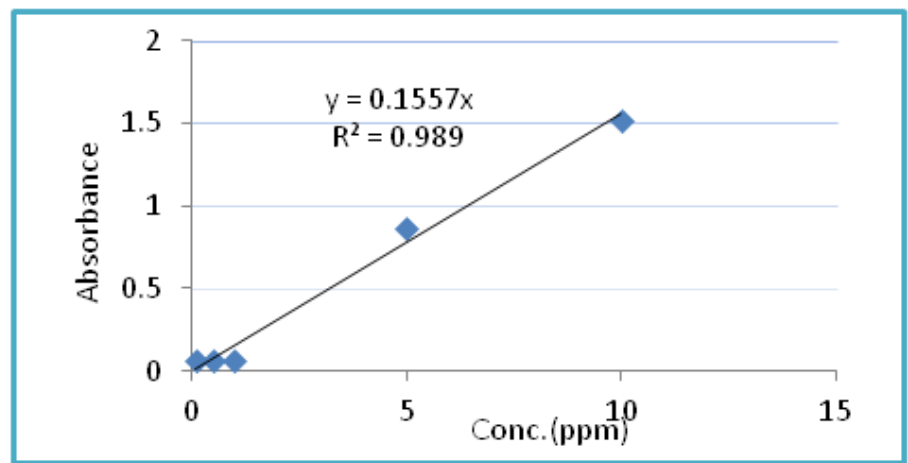

Figure 5:- shows the calibration graph for MB.

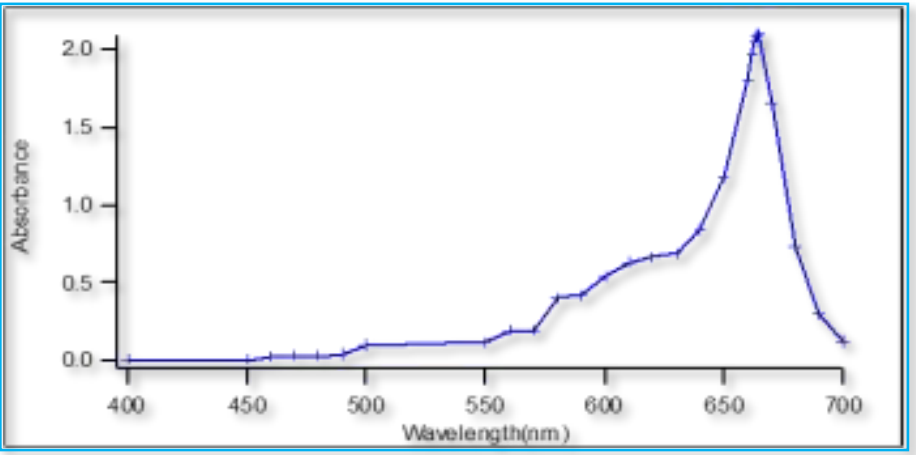

Figure 6:- UV-visible absorption spectra of methylene blue

The rate constant was measured using fitting as can be shown in figure 7. from the figure it's clear that the rate constant increased when the distance between the iodization electrodes decreased .The reason for this its clearly shown in table 2 .the contact angle increased and the adsorbed of the dye less on the surface so it's no internal inside the tubes therefore the absorbance inside the tube less and the amount of absorbed MB less therefore the release become faster. From the result, its show that the controlling of release can be done by controlling the tubes diameter from controlling the distance between the electrodes in the anodisation process. 

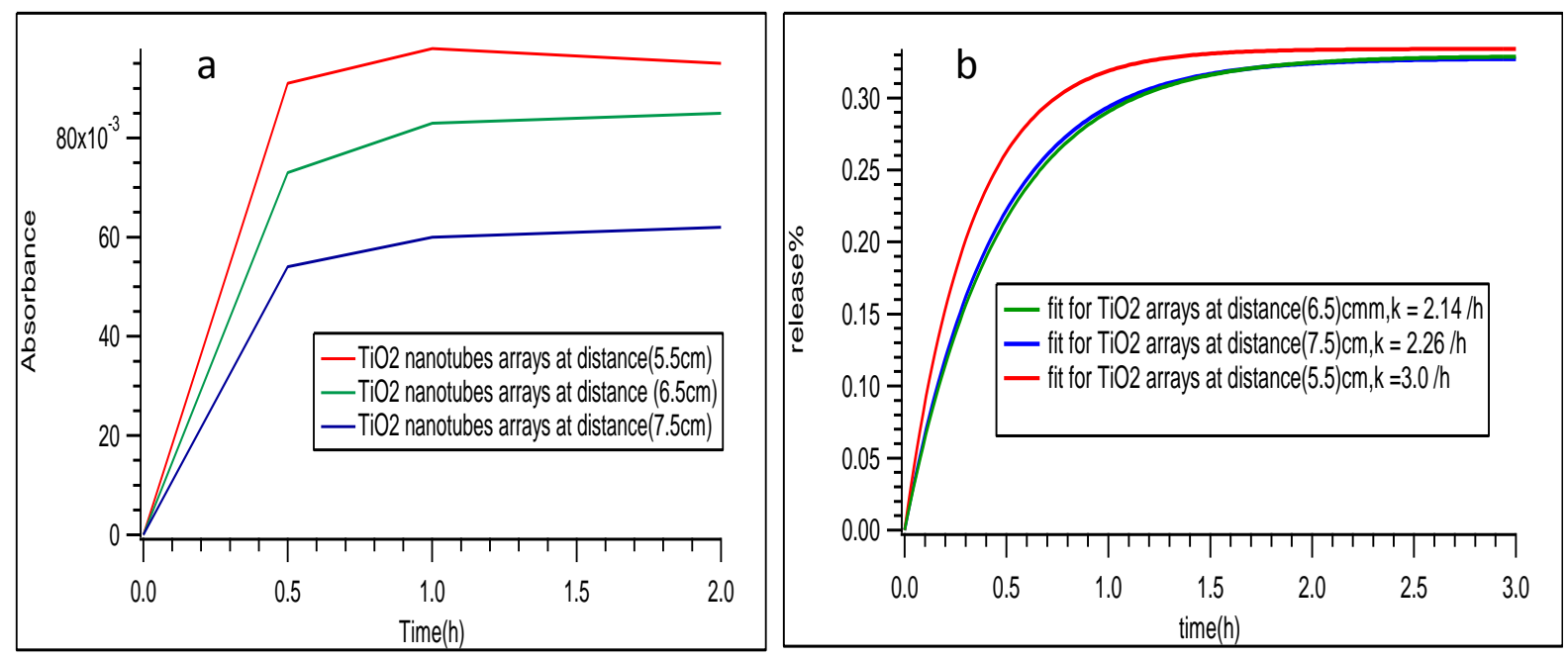

Figure7: shows two states (a) the release without fitting (b) the release with fitting.

$\mathbf{1} \% \mathrm{~W} / \mathrm{W}$ ) poly vinyl alcohol, pva. The titanium arrays was dipped in MB for (24) hours then the arrays was dried in air and the dipped in 1\%PVA for 5 mints then dried again in air. The arrays become coated with the thin layer of polymer PVA. Then the release was started when the coated arrays was dipped in (25) $\mathrm{ml}$ of water.

\section{CONCLUSION:-}

$\mathrm{TiO}_{2}$ nanotubes can be prepared from anodisation method which is greener and environmentally suitable, cheap and best as compared to conventional methods. The distance between the electrodes affects the morphology of $\mathrm{TiO}_{2}$ nanotubes. Morphology is mainly responsible for their applications, such as drug release.

\section{References:-}

1. GhicovA, T.H., Macak J M, Schmuki P, Titanium oxide nanotubes prepared in phosphate electrolytes[J].Electrochemistry Communications, 2005. 7: p. 505-509.

2. TsuchiyaH, M.J.M., Sieber I, Taveira L, GhicovA, and S.P. SirotnakI, Self-organized porous WO3 formed in NaF electrolytes [J]. Electrochemistry Communications, 2005. 7: p. 295-298.

3. TsuchiyaH, S.P., Thick self-organized porous zirconium oxide formed in $\mathrm{H} 2 \mathrm{SO} 4$ /NH 4 F electrolytes[J]. ElectrochemistryCommunications 2004. 6: p. 1131-1134.

4. PauloseM, V.O.K., MOR G K, GRIMES C A, ONG K,Unprecedented ultra-high hydrogen gas sensitivity in undoped titania nanotubes. [J]. Nanotechnology,, 2006 17: p. 398-402.

5. MacakJ M, S.-S.F., Schmuki P, Efficient oxygen reduction on layers of ordered TiO2 nanotubes loaded with Au nanoparticles[J]. Electrochemistry Communications, 2007. 9: p. 1783-1787.

6. OnodaaK, N.S., FUJIEDAA T,YOSHIKAWA S,The superiority of Ti plate as the substrate of dye-sensitized solar cells,. [J]. Solar Energy Materials and Solar Cells, 2007. 91: p. 1176-1181.

7. OhhJ, L.J.H., JEONG Y, KIM Y J, CHI C S., Microstructural characterization of biomedical titanium oxide film by electrochemical method. [J]. Surface and Coating Technology,, 2005. 198: p. 247-252.

8. XiLin Xiao, e.a., Biocompatibility and in vitro antineoplastic drug-loaded trial of titania nanotubes prepared by anodic oxidation of a pure titanium ): Science in China Series B-Chemistry, 2009. 52(12): p. 2161-2165.

9. Albu, S.P. and P. Schmuki, TiO(2) nanotubes grown in different organic electrolytes: Two-size selforganization, single vs. double-walled tubes, and giant diameters. Physica Status Solidi-Rapid Research Letters, 2010. 4(8-9): p. 215-217.

10. Albu, S.P., D. Kim, and P. Schmuki, Growth of Aligned TiO2 Bamboo-Type Nanotubes and Highly Ordered Nanolace. Angewandte Chemie International Edition, 2008. 47(10): p. 1916-1919.

11. Allam, N.K. and C.A. Grimes, Formation of vertically oriented TiO2 nanotube arrays using a fluoride free $\mathrm{HCl}$ aqueous electrolyte. Journal of Physical Chemistry C, 2007. 111(35): p. 13028-13032.

12. Beranek, R., H. Hildebrand, and P. Schmuki, Self-organized porous titanium oxide prepared in H2SO4/HF electrolytes. Electrochemical and Solid State Letters, 2003. 6(3): p. B12-B14.

13. Bauer, S., S. Kleber, and P. Schmuki, TiO2 nanotubes: Tailoring the geometry in H3PO4/HF electrolytes. Electrochemistry Communications, 2006. 8(8): p. 1321-1325. 
14. Sun, L.D., et al., Effect of electric field strength on the length of anodized titania nanotube arrays. Journal of Electroanalytical Chemistry, 2009. 637(1-2): p. 6-12.

15. Carp, O., C.L. Huisman, and A. Reller, Photoinduced reactivity of titanium dioxide. Progress in Solid State Chemistry, 2004. 32(1-2): p. 33-177.

16. Behnajady, M.A., et al., Enhancement of photocatalytic activity of TiO(2) nanoparticles by silver doping: Photodeposition versus liquid impregnation methods. Global Nest Journal, 2008. 10(1): p. 1-7.

17. Catauro, M., M.G. Raucci, and M.A. Continenza, Release kinetics of ampicillin, biocompatibility tests with a fibroblast strain of a Zirconia gel glass. Letters in Drug Design \& Discovery, 2007. 4(6): p. 453-459.

18. Adiga, S.P., et al., Nanoporous membranes for medical and biological applications. Wiley Interdisciplinary Reviews-Nanomedicine and Nanobiotechnology, 2009. 1(5): p. 568-581.

19. Kumaresh S Soppimath, T.M.A., Anandrao R Kulkarni, Walter E Rudzinski,, , Biodegradable polymeric nanoparticles as drug delivery devices. Journal of Controlled Release,. 2001. 70(2): p. p. 1-20.

20. Langer, R. and N.A. Peppas, Advances in biomaterials, drug delivery, and bionanotechnology. Aiche Journal, 2003. 49(12): p. 2990-3006.

21. Al-Abdullah, Z.T.Y., The Study of Growth Mechanism of TiO 2 Nanotubes and

22. Their Applications.phd thesis, 2012.

23. Langer, R.a.N.A.P., Advances in biomaterials, drug delivery, and bionanotechnology. Aiche Journal, 2003. 49(12). p. p. 2990-3006. 